\title{
WHERE SHE LIVES
}

This is the time when the man and the moment come together. -Richard M. Nixon

\author{
When Mr. Nixon \\ comes to dinner \\ it's Wichita, someplace \\ lonely, some anxious kitchen \\ where it hums \\ like dwindled flies \\ warming on a window sill. \\ In the next apartment \\ the whole population \\ of some other planet \\ fuck, a commotion \\ cheerless as those cheers \\ heard distantly \\ on football afternoons- \\ or something stumbles \\ thoughtless, half Dracula \\ and half November, \\ through the bedroom mirror: \\ the pale husband \\ reciting in a voice \\ as clear as water \\ draining in a sink \\ of severed hands \\ why the lightbulb \\ in the lamp is loose \\ or on the table \\ why the bread just sits there \\ soft, inexplicably white \\ beside the broken radio.
}

